\title{
Oligometastatic Disease in the Peritoneal Space with Gastrointestinal Cancer
}

\author{
Beate Rau ${ }^{a} \quad$ Andreas Brandla ${ }^{a}$ Andreas Pascher ${ }^{a} \quad$ Wieland Raue ${ }^{a} \quad$ Paul Sugarbaker $^{b}$ \\ ${ }^{a}$ Department of General Surgery, Charité - Universitätsmedizin Berlin, Campus Virchow and Mitte, Berlin, Germany; \\ ${ }^{\mathrm{b}}$ MedStar Washington Hospital Center, Washington, DC, USA
}

\section{Keywords}

Peritoneal metastasis · Hyperthermic intraperitoneal chemotherapy, HIPEC - Cytoreductive surgery .

Peritoneal carcinomatosis index, $\mathrm{PCl}$.

Palliative treatment in gastrointestinal cancer

\section{Summary}

Objectives: Treatment options for patients with gastrointestinal cancer and oligometastastic disease remain the domain of the medical oncologist. However, in selected cases, attempts to remove or destroy the tumor burden seem appropriate. Background Data: During the last decade, the treatment of localized and isolated tumor nodules, such as lung, liver or peritoneal metastasis, has changed. Previously, these patients with metastatic disease only received palliative chemotherapy. Combined treatment approaches and new techniques demonstrate that additional surgery to destroy or remove the metastases seem to be of major benefit to patients. Methods: The recently published important literature regarding peritoneal metastases and oligometastases in gastrointestinal cancer was analyzed. Results: The most important factor in the treatment of peritoneal metastases and in cytoreductive surgery is patient selection. Resection of peritoneal metastases should be considered. Hyperthermic intraperitoneal chemotherapy is feasible. However, further results of randomized trials are necessary. Several randomized trials are on the way and will be available in 1-2 years. Systemic chemotherapy alone as an adequate management plan for all sites of metastatic disease is not compatible with a high standard of care. Formulating an optimal plan combining re-operative surgery with regional plus systemic chemotherapy is a necessary task of the multidisciplinary team. Conclusions: In oligometastastic disease of gastrointestinal cancer origin, the selection process is the most important factor for survival. Further studies are needed to determine optimal treatment options.

(c) 2017 S. Karger GmbH, Freiburg

\section{Introduction}

Peritoneal metastases (PM) are considered to have a poor prognosis, and until 1980, palliative procedures were the only treatment option offered. After that time, additional regimens, such as intraperitoneal chemotherapy or hyperthermic intraperitoneal chemotherapy (HIPEC), were developed to increase the chemotherapy dosage at the tumor site and to improve the outcome for the patients. Nearly 20 years ago, cytoreductive surgery (CRS) was implemented into the treatment strategies for PM, and the combination of CRS and HIPEC turned out to offer long-term benefits, with a 5 -year disease-free survival (DFS) rate of up to $55 \%$ in selected patients $[1,2]$.

In the case of systemic metastases, two main pathways are of interest for therapeutic decision making: one in which the diaspora resembles an imperial colonization where the population spreads widely and conquers the new host land (i.e. an aggressive cancer that disseminates to few organs). In contrast, the colonization may represent a limited number of outposts with limited growth potential (i.e. a less aggressive cancer that disseminates to few organs). Whether the diaspora is systemic or oligometastastic may depend on the types of mutation present in the cancer cells while they settle in the homeland, the environment of the homeland, and the persistence of the original tumor site [3].

The most common origins for secondary PM are ovarian, gastric, and colorectal cancer (CRC) and appendix neoplasms. In the French registry of PM, the underlying primary tumor was CRC in $40 \%$ of the cases, gastric cancer in $12 \%$, as well as appendiceal cancer and small intestine cancer in $4 \%$ each [4].

\section{KARGER}

(c) 2017 S. Karger GmbH, Freiburg

Fax +497614520714 
Prognostic factors such as the completeness of cytoreduction (CCR score) and the extent of peritoneal seeding expressed by the peritoneal carcinomatosis index (PCI) are important to the treatment of this disease [5]. Cytoreduction is the strongest prognostic factor. The aim of CRS is to obtain complete macroscopic cytoreduction (CCR-0/1). The residual disease is classified intraoperatively using the CCR score. CCR-0 indicates no visible residual tumor and CCR-1 residual tumor nodules $\leq 2.5 \mathrm{~mm}$. CCR-2 and CCR-3 indicate residual tumor nodules between $2.5 \mathrm{~mm}$ and 2.5 $\mathrm{cm}$ as well as $>2.5 \mathrm{~cm}$, respectively [6, 7]. The PCI has been developed to categorize the tumor burden of peritoneal surface malignancy (PSM), with the lowest value being 0 and the highest 39 [8]. PCI influences the prognosis of the patient. The higher the PCI, the worse is the outcome of the patients [8]. Upper gastrointestinal tumors such as esophageal, gastric, pancreatic or hepatobiliary cancer do very badly when the PCI is $>10[4,9]$. Unless it is an emergency and the patient is asymptomatic, these patients do not profit from multivisceral resection and CRS. In lower gastrointestinal tumors including appendix cancer, colon cancer, and rectal cancer, CRS can be beneficial if the PCI is low and the morphology of the PSM is mucinous. Especially in mucinous PSM, even patients with a high PCI are accepted for CRS [10].

The prognosis for select patients with secondary PM treated with CRS and HIPEC ranges from a median survival of 9-11 months for those with gastric cancer to a survival of 40-50 months for those with colorectal or epithelial ovarian cancer [11-13]. In contrast, untreated patients have a survival of only a few months.

However, in cases of gastrointestinal cancer, isolated PM are rare and usually occur in combination with liver or lung metastases.

Among the current evolving concepts in the treatment of oligometastastic disease, including PM, the identification of prognostic factors is essential to ensure appropriate patient selection.

In the following, we provide an overview of oligometastastic gastrointestinal primary cancers.

\section{Synchronous and Metachronous Metastases}

Metastases are synchronous when they are detected along with the primary cancer. Synchronous metastases of gastrointestinal cancer are considered to indicate a worse prognosis than metachronous metastases. Survival rates are significantly different when metastasis is present at or within 1 month before diagnosis compared with metastasis which developed 12 months after the primary diagnosis $(\mathrm{p}<0.0001)[14]$.

Metastatic disease occurring 12 months after treatment of the primary cancer is considered as metachronous metastatic disease and presents a better prognosis. However, number of metastases, complete resection of the metastases, infiltration depth of the primary cancer, and lymph node involvement are prognostically relevant $[15,16]$.

When metachronous metastases are completely resectable, it is under debate whether induction chemotherapy has an effect on survival. Some arguments promote the use of induction chemo- therapy to observe the response to treatment and to exclude patients from complex surgical treatment options when the disease progresses under systemic chemotherapy.

\section{Gastric Cancer}

In a population of 5,220 patients with gastric cancer, 39\% presented distant metastases and 706 patients (34\%) were diagnosed with peritoneal disease; of these, 491 had only isolated PM [17]. The median survival without chemotherapy was 3.4 months, whereas it was 7.7 months with chemotherapy. However, the authors could not demonstrate any significant improvement over the last 20 years in patients with PM.

The recommendation in the current National Comprehensive Cancer Network guidelines for stage IV gastric cancer patients is palliative care including best supportive care or, in selected patients, palliative chemotherapy within clinical studies [18]. Surgical treatment is only required for the palliation of tumor-related symptoms such as bleeding, obstruction, or perforation [19].

\section{Peritoneal Metastases}

The optimal treatment strategy for disseminated gastric cancer is still under debate. For limited PM with a PCI $<10$, the aggressive, multimodal treatment of PM of gastric cancer with CRS and HIPEC can be justified when complete cytoreduction is achievable (table 1). In a retrospective analysis, the clinical outcomes of 38 patients treated with gastrectomy, CRS, and HIPEC for advanced gastric cancer with PM were compared with patients with advanced gastric cancer with no evidence of PM as well as with patients who underwent palliative treatment (with and without gastrectomy). The median survival time after the first diagnosis of PM for gastric cancer was 17.2 months in the CRS and HIPEC group, compared with 11.0 months for those treated with gastrectomy and chemotherapy alone, resulting in a twofold increase in the 2-year survival rate (35.8 vs. $16.9 \%$ ) [20]. These results were supported by other publications which reported that in selected patients with a $\mathrm{PCI}<$ 10 , a complete CRS can result in a better outcome compared with chemotherapy alone [19, 21-23].

The important randomized controlled trial reported by Yang et al. [24] showed a significant survival advantage in gastric cancer patients with peritoneal metastases who had resection plus HIPEC. The median survival was 11 months with CRS plus HIPEC versus 6.5 months with CRS alone $(\mathrm{p}=0.046)$. The authors conclude that with synchronous gastric PM, CRS plus HIPEC with mitomycin C and cisplatin may improve survival with acceptable morbidity [24]. Glehen et al. [25] started with a randomized trial named GASTRICHIP. It is a prospective, open, randomized multicenter phase III clinical study with two arms that aims to evaluate the effects of HIPEC with oxaliplatin on patients with gastric cancer involving the serosa and/or with lymph node involvement and/or with positive cytology at peritoneal washing, treated with perioperative systemic chemotherapy and D1-D2 curative gastrectomy [25]. Another prospective, randomized multicenter phase III clinical study 
Table 1. PCI cut-off point in gastric cancer

\begin{tabular}{llccl}
\hline Investigator & $\begin{array}{l}\text { Year of } \\
\text { publication }\end{array}$ & $\mathrm{n}$ & $\begin{array}{l}\text { PCI } \\
\text { cut-off }\end{array}$ & Significance \\
\hline Boerner et al. [20] & 2016 & 38 & 10 & $\begin{array}{l}\text { median survival time 17.2 months } \\
(95 \% \text { CI 10.1-24.2 months) }\end{array}$ \\
\hline Yang et al. [43] & 2010 & 30 & 20 & $\begin{array}{l}\text { median survival time PCI }<20 \text { was } \\
27.7 \text { months }(95 \% \text { CI } 15.2-40.3 \text { months }) \\
\text { and high PCI }>20 \text { was } 6.4 \text { months } \\
(95 \% \text { CI 3.8-8.9 months) }(\mathrm{p}=0.000)\end{array}$ \\
\hline Glehen et al. [11] & 2010 & 159 & 12 & mean PCI was 9.4 (SD: 7.7) \\
\hline Yonemura et al. [44] & 2010 & 95 & $<6$ & $\begin{array}{l}\text { median survival time with PCI }<6 \text { was } \\
33.6 \text { months and PCI }>6 \text { was 13.2 months }\end{array}$ \\
\hline Canbay et al. [45] & 2014 & 194 & $<6$ & \\
\hline Coccolini et al. [46] & 2015 & 748 & 12 & meta-analysis \\
\hline PCI = Peritoneal carcinomatosis index; CI = confidence interval; SD = standard deviation.
\end{tabular}

with two arms called GASTRIPEC trial is open. 180 patients with histologically proven gastric cancer (including cancer of the esophagogastric junction and synchronous peritoneal carcinomatosis) are included. There are two treatment groups (A and B) with 90 patients each. The chemotherapy applied intravenously is the same in both groups and is approved for the treatment of gastric cancer. Patients with negative or unknown HER-2 status will be administered epirubicin, oxaliplatin, and capecitabine (EOX). Patients with positive HER-2 status will be treated with cisplatin, capecitabine, and trastuzumab (CCT) [26].

\section{Oligometastases}

The discussion of treatment strategies for stage IV gastric cancer is ongoing, especially in terms of whether surgical procedures should be integrated. New molecular and genomic research findings related to gastric cancer have identified four possible major genomic subtypes of gastric cancer - i.e. tumors infected with Epstein-Barr virus, tumors with microsatellite instability, genomically stable tumors, and chromosomally unstable tumors - which may help to select patients with oligometastastic disease who are good candidates for specific treatment strategies, including CRS [27].

In stage IV gastric cancer, aggressive CRS combined with additional chemotherapy, such as HIPEC, should only be offered to patients with limited disease. Some clinicians limit CRS and HIPEC to patients who have responded to chemotherapy.

\section{Colorectal Cancer}

In newly diagnosed CRC, disseminated disease will occur in $25 \%$ of the patients. Most of these are patients with liver metastases; therefore, treatment schedules that include surgery were established.

The incidence and prognosis of synchronous PM was demonstrated in a population-based data set that included 18,738 cases of CRC. PM was diagnosed in 904 patients (5\%). The prognosis of synchronous PM remains poor, with a median survival of 8 months; it is even worse when concomitant metastases in other organs are present. Synchronous PM of CRC are more frequent among younger patients and among those with advanced $\mathrm{T}$ stages, mucinous adenocarcinoma (MAC), right-sided tumors, and tumors that are poorly differentiated [28].

\section{Peritoneal Metastases}

Approximately 5-10\% of patients with CRC present with synchronous metastases of the peritoneum at the time of initial colon resection, and $20-50 \%$ may present with metachronous disease [29]. Little is known about the development of PM. The detachment of tumor cells into the peritoneum associated with the invasion of the peritoneal surface are often explanations; however, these processes require a molecular mechanism that is not yet clear. The histological subtypes adenocarcinoma (AC), MAC, and signet ring cell carcinomas (SC) are of major prognostic importance. The incidence of MAC and SC is approximately $10-15 \%$ and $1 \%$ of all CRC, respectively, but these subtypes are associated with young age, advanced tumor stage, a distinct molecular pattern, and worse prognosis compared with classical AC [30, 31].

In a large, nationwide, population-based study, Razenberg et al. [32] showed an incidence of $22 \%$ of mucinous carcinoma in patients with peritoneal carcinomatosis from CRC and a superior median survival of 13 months compared with those with AC (8.9 months) and SC (7.1 months).

Da Silva and Sugarbaker [33] showed that a PCI $>20$ and lymph node positivity, but not mucinous type, have an impact on patient survival. The only randomized controlled trial with an 8-year follow-up was published by Verwaal et al. [34, 35] and showed a median survival of 48 months as well as a 5 -year survival of $45 \%$ for patients with complete cytoreduction; furthermore, the study identified CCR and extent of intra-abdominal tumor spread as prognostic factors.

In CRC, PCI is again a significant factor regarding patient survival (table 2). However, large retrospective studies showed 5-year 
Table 2. PCI cut-off point in colorectal cancer

\begin{tabular}{lllll}
\hline Investigator & $\begin{array}{l}\text { Year of } \\
\text { publication }\end{array}$ & $\mathrm{n}$ & $\begin{array}{l}\text { PCI } \\
\text { cut-off }\end{array}$ & Significance \\
\hline $\begin{array}{l}\text { da Silva and } \\
\text { Sugarbaker [33] }\end{array}$ & 2006 & 156 & 20 & $\begin{array}{l}\text { median survival: 41 versus 16 months, } \\
\mathrm{p}=0.004\end{array}$ \\
\hline Elias et al. [40] & 2014 & 139 & 15 & $\begin{array}{l}5 \text {-year OS } 48 \% \text { with PCI }<15 \text { versus } \\
12 \% \text { PCI }>15, \mathrm{p}<0.0001\end{array}$ \\
\hline Goéré et al. [6] & 2015 & 180 & 17 & HR: 0.64; range 0.38-1.09 \\
\hline Faron et al. [5] & 2016 & 173 & 12 & $\begin{array}{l}\text { PCI was related to OS with a HR of 1.1 } \\
\text { (p }=0.0001 \text { ) for each increase of 1 PCI point }\end{array}$ \\
\hline PCI = Peritoneal carcinomatosis index; OS = overall survival; HR $=$ hazard ratio.
\end{tabular}

survival rates of up to $27 \%$, with CCR $[36,37]$ and lymph node metastases at the time of CRS and HIPEC [38] being major prognostic factors.

It was recently reported by van Oudheusden et al. [39] that in a small patient group, patients with peritoneal carcinomatosis of signet cell CRC who underwent CRS and HIPEC had a poor outcome, with a median survival of 14 months.

The French randomized trial PRODIGE 7 included 264 patients with PM with a PCI $<24$ of colorectal origin. The patients underwent complete cytoreduction in both arms. Directly after CRS, one group received HIPEC with oxaliplatin while the other group did not. Postoperatively, both groups received chemotherapy for 6 months. The trial is closed and the results will be available soon.

\section{Summary of Oligometastases from Colorectal Cancer}

CRS and additional multimodal treatment in oligometastastic disease could be considered in cases where the disease is at least stable and complete resection of all tumor lesions seems possible. In terms of a surgical approach, CRC for oligometastastic diseaseonly patients should be discussed only for those with a PCI $<12$, who have no SC [39], and who are responsive to preoperative chemotherapy. Patients with small bowel involvement [40] and more than three liver metastases [41] should be excluded from surgical treatment.

It has been shown that the extent of the peritoneal tumor mass, which is determined by the PCI, is the best prognostic indicator, as reported by Sugarbaker [42] in 1998. It has been shown that the PCI correlates with the overall survival when complete cytoreduc- tion and HIPEC are performed [5]. A recently published study by Goéré et al. [6] proposed that the PCI cut-off for survival benefit is a PCI of 17. However, long-term benefits are possible with CRC when the PCI is less than 12 . PCIs $>17$ are correlated with short survival, and surgery is not indicated in these patients [5]. Patients with PCIs between 12 and 17 should not undergo surgery if additional organ metastases are present, and complete resection is not possible without major resections in patients with no symptoms.

\section{Conclusion}

Oligometastastic disease focusing on PM should be considered for CRS and HIPEC only in select patients. The selection process should consider the molecular biology of the primary cancer site, the PCI, the infiltration depth of the primary and lymph node metastases, a differentiation between synchronous and metachronous metastases, the onset of the metastases, the response to chemotherapy, and the CCR. Systemic chemotherapy alone as an adequate management plan for all sites of metastatic disease is not compatible with a high standard of care. Formulating an optimal plan combining re-operative surgery with regional plus systemic chemotherapy is a necessary task of the multidisciplinary team.

\section{Disclosure Statement}

Herewith the authors confirm that they have nothing to declare concerning conflict of interest.

\section{References}

1 Smeenk RM, Verwaal VJ, Zoetmulder FA: Learning curve of combined modality treatment in peritoneal surface disease. Br J Surg 2007;94:1408-1414

2 Chua TC, Moran BJ, Sugarbaker PH, et al: Early- and long-term outcome data of patients with pseudomyxoma peritonei from appendiceal origin treated by a strategy of cytoreductive surgery and hyperthermic intraperitoneal chemotherapy. J Clin Oncol 2012;30:2449-2456.

3 Reyes DK, Pienta KJ: The biology and treatment of oligometastatic cancer. Oncotarget 2015;6:8491-8524.
4 Glehen O, Gilly FN, Boutitie F, Bereder JM, Quenet F, Sideris L, Mansvelt B, Lorimier G, Msika S, Elias D: Toward curative treatment of peritoneal carcinomatosis from nonovarian origin by cytoreductive surgery combined with perioperative intraperitoneal chemotherapy: a multi-institutional study of 1,290 patients. Cancer 2010;116:5608-5618.

5 Faron M, Macovei R, Goere D, Honore C, Benhaim L, Elias D: Linear relationship of peritoneal cancer index and survival in patients with peritoneal metastases from colorectal cancer. Ann Surg Oncol 2016;23:114-119.
6 Goéré D, Souadka A, Faron M, Cloutier AS, Viana B, Honore C, Dumont F, Elias D: Extent of colorectal peritoneal carcinomatosis: attempt to define a threshold above which HIPEC does not offer survival benefit: a comparative study. Ann Surg Oncol 2015;22:2958-2964.

7 Glehen O, Osinsky D, Cotte E, Kwiatkowski F, Freyer G, Isaac S, Trillet-Lenoir V, Sayag-Beaujard AC, Francois $\mathrm{Y}$, Vignal J, Gilly FN: Intraperitoneal chemohyperthermia using a closed abdominal procedure and cytoreductive surgery for the treatment of peritoneal carcinomatosis: morbidity and mortality analysis of 216 consecutive procedures. Ann Surg Oncol 2003;10:863-869. 
8 Glehen O, Kwiatkowski F, Sugarbaker PH, Elias D, Levine EA, De Simone M, Barone R, Yonemura Y, Cavaliere F, Quenet F, Gutman M, Tentes AA, Lorimier G, Bernard JL, Bereder JM, Porcheron J, GomezPortilla A, Shen P, Deraco M, Rat P: Cytoreductive surgery combined with perioperative intraperitoneal chemotherapy for the management of peritoneal carcinomatosis from colorectal cancer: a multi-institutional study. J Clin Oncol 2004;22:3284-3292.

9 Yonemura Y, Elnemr A, Endou Y, Hirano M, Mizumoto A, Takao N, Ichinose M, Miura M, Li Y: Multidisciplinary therapy for treatment of patients with peritoneal carcinomatosis from gastric cancer. World J Gastrointest Oncol 2010;2:85-87.

10 Moran B, Cecil T, Chandrakumaran K, Arnold S, Mohamed F, Venkatasubramaniam A: The results of cytoreductive surgery and hyperthermic intraperitoneal chemotherapy in 1200 patients with peritoneal malignancy. Colorectal Dis 2015;17:772-778.

11 Glehen O, Gilly FN, Arvieux C, Cotte E, Boutitie F, Mansvelt B, Bereder JM, Lorimier G, Quenet F, Elias D: Peritoneal carcinomatosis from gastric cancer: a multi-institutional study of 159 patients treated by cytoreductive surgery combined with perioperative intraperitoneal chemotherapy. Ann Surg Oncol 2010;17: 2370-2377.

12 Bakrin N, Cotte E, Golfier F, Gilly FN, Freyer G, Helm W, Glehen O, Bereder JM: Cytoreductive surgery and hyperthermic intraperitoneal chemotherapy (HIPEC) for persistent and recurrent advanced ovarian carcinoma: a multicenter, prospective study of 246 patients. Ann Surg Oncol 2012;19:4052-4058.

13 Elias D, Gilly F, Boutitie F, Quenet F, Bereder JM, Mansvelt B, Lorimier G, Dube P, Glehen O: Peritoneal colorectal carcinomatosis treated with surgery and perioperative intraperitoneal chemotherapy: retrospective analysis of 523 patients from a multicentric French study. J Clin Oncol 2010;28:63-68.

14 Mekenkamp LJ, Koopman M, Teerenstra S, van Krieken JH, Mol L, Nagtegaal ID, Punt CJ: Clinicopathological features and outcome in advanced colorectal cancer patients with synchronous vs metachronous metastases. Br J Cancer 2010;103:159-164.

15 Salah S, Ardissone F, Gonzalez M, Gervaz P, Riquet M, Watanabe K, Zabaleta J, Al-Rimawi D, Toubasi S, Massad E, Lisi E, Hamed OH: Pulmonary metastasectomy in colorectal cancer patients with previously resected liver metastasis: pooled analysis. Ann Surg Oncol 2015; 22:1844-1850.

16 Renehan AG, Egger M, Saunders MP, O’Dwyer ST: Impact on survival of intensive follow-up after curative resection for colorectal cancer: systematic review and meta-analysis of randomised trials. BMJ 2002;324:813.

17 Thomassen I, van Gestel YR, Aalbers AG, van Oudheusden TR, Wegdam JA, Lemmens VE, de Hingh IH: Peritoneal carcinomatosis is less frequently diagnosed during laparoscopic surgery compared to open surgery in patients with colorectal cancer. Eur J Surg Oncol 2014;40:511-514.

18 Ajani JA, Bentrem DJ, Besh S, et al: Gastric cancer, version 2.2013: featured updates to the NCCN Guidelines. J Natl Compr Canc Netw 2013;11:531-546.

19 Jeong O, Park YK, Choi WY, Ryu SY: Prognostic significance of non-curative gastrectomy for incurable gastric carcinoma. Ann Surg Oncol 2014;21:2587-2593.

20 Boerner T, Graichen A, Jeiter T, Zemann F, Renner P, März L, Soeder Y, Schlitt HJ, Piso P, Dahlke MH: CRSHIPEC prolongs survival but is not curative for patients with peritoneal carcinomatosis of gastric cancer. Ann Surg Oncol 2016;23:3972-3977.
21 Hultman B, Lind P, Glimelius B, Sundbom M, Nygren P, Haglund U, Mahteme H: Phase II study of patients with peritoneal carcinomatosis from gastric cancer treated with preoperative systemic chemotherapy followed by peritonectomy and intraperitoneal chemotherapy. Acta Oncol 2013;52:824-830.

22 Yarema RR, Ohorchak MA, Zubarev GP, Mylyan YP, Oliynyk YY, Zubarev MG, Gyrya PI, Kovalchuk YJ, Safiyan VI, Fetsych TG: Hyperthermic intraperitoneal chemoperfusion in combined treatment of locally advanced and disseminated gastric cancer: results of a single-centre retrospective study. Int J Hyperthermia 2014;30:159-165.

23 Goéré D, Gras-Chaput N, Auperin A, Flament C, Mariette $\mathrm{C}$, Glehen $\mathrm{O}$, Zitvogel L, Elias D: Treatment of gastric peritoneal carcinomatosis by combining complete surgical resection of lesions and intraperitoneal immunotherapy using catumaxomab. BMC Cancer 2014;14:148.

24 Yang XJ, Huang CQ, Suo T, Mei LJ, Yang GL, Cheng FL, Zhou YF, Xiong B, Yonemura Y, Li Y: Cytoreductive surgery and hyperthermic intraperitoneal chemotherapy improves survival of patients with peritoneal carcinomatosis from gastric cancer: final results of a phase III randomized clinical trial. Ann Surg Oncol 2011;18:1575-1581.

25 Glehen O, Passot G, Villeneuve L, Vaudoyer D, BinDorel S, Boschetti G, Piaton E, Garofalo A: GASTRICHIP: D2 resection and hyperthermic intraperitoneal chemotherapy in locally advanced gastric carcinoma: a randomized and multicenter phase III study. BMC Cancer 2014;14:183.

26 Rau B, Löffler M, Rau HG, Sulkowski U, Kuhlmann J, Weimann A, Keck T, Angele M, Topp S, Koenigsrainer A, Kuhnt E, Schwarzkopf M, Knoefel W, Kretzschmar A, Heinemann V, Thuss-Patience P: Perioperative chemotherapy and cytoreductive surgery with versus without HIPEC in gastric cancer with limited peritoneal metastases: a randomized phase III study (GASTRIPEC). J Clin Oncol 2015;33(suppl):abstr TPS4132.

27 Cui J, Yin Y, Ma Q, Wang G, Olman V, Zhang Y, Chou WC, Hong CS, Zhang C, Cao S, Mao X, Li Y, Qin S, Zhao S, Jiang J, Hastings P, Li F, Xu Y: Comprehensive characterization of the genomic alterations in human gastric cancer. Int J Cancer 2015; 137:86-95.

28 Lemmens VE, Klaver YL, Verwaal VJ, Rutten HJ, Coebergh JW, de Hingh IH: Predictors and survival of synchronous peritoneal carcinomatosis of colorectal origin: a population-based study. Int J Cancer 2011; 128:2717-2725

29 Cao C, Yan TD, Black D, Morris DL: A systematic review and meta-analysis of cytoreductive surgery with perioperative intraperitoneal chemotherapy for peritoneal carcinomatosis of colorectal origin. Ann Surg Oncol 2009;16:2152-2165.

30 Lin J, Qiu M, Xu R, Dobs AS: Comparison of survival and clinicopathologic features in colorectal cancer among African American, Caucasian, and Chinese patients treated in the United States: results from the surveillance epidemiology and end results (SEER) database. Oncotarget 2015;20;6:33935-33943.

31 Nitsche U, Friess H, Agha A, Angele M, Eckel R, Heitland W, Jauch KW, Krenz D, Nüssler NC, Rau HG, Ruppert R, Schubert-Fritschle G, Wilhelm D, Werner J, Engel J: Prognosis of mucinous and signet-ring cell colorectal cancer in a population-based cohort. J Cancer Res Clin Oncol 2016;142:2357-2366.

32 Razenberg LG, van Gestel YR, Lemmens VE, de Wilt JH, Creemers GJ, de Hingh IH: The prognostic relevance of histological subtype in patients with peritoneal metastases from colorectal cancer: a nationwide population-based study. Clin Colorectal Cancer 2015; 14:e13-19.
33 da Silva RG, Sugarbaker PH: Analysis of prognostic factors in seventy patients having a complete cytoreduction plus perioperative intraperitoneal chemotherapy for carcinomatosis from colorectal cancer. J Am Coll Surg 2006;203:878-886.

34 Verwaal VJ, Bruin S, Boot H, van Slooten G, van Tinteren H: 8-year follow-up of randomized trial: cytoreduction and hyperthermic intraperitoneal chemotherapy versus systemic chemotherapy in patients with peritoneal carcinomatosis of colorectal cancer. Ann Surg Oncol 2008; 15:2426-2432.

35 Verwaal VJ, van Ruth S, de Bree E, van Sloothen GW, van Tinteren H, Boot H, Zoetmulder FA: Randomized trial of cytoreduction and hyperthermic intraperitoneal chemotherapy versus systemic chemotherapy and palliative surgery in patients with peritoneal carcinomatosis of colorectal cancer. J Clin Oncol 2003;21: 3737-3743.

36 Elias D, Di Pietrantonio D, Boulet T, Honore C, Bonnet S, Goere D, Kohneh-Shahri N, Raynard B: 'Natural history' of complete cytoreductive surgery with hyperthermic intraperitoneal chemotherapy. Eur J Surg Oncol 2009;35:434-438.

37 Glehen O, Mohamed F, Gilly FN: Peritoneal carcinomatosis from digestive tract cancer: new management by cytoreductive surgery and intraperitoneal chemohyperthermia. Lancet Oncol 2004;5:219-228.

38 Baumgartner JM, Tobin L, Heavey SF, Kelly KJ, Roeland EJ, Lowy AM: Predictors of progression in highgrade appendiceal or colorectal peritoneal carcinomatosis after cytoreductive surgery and hyperthermic intraperitoneal chemotherapy. Ann Surg Oncol 2015;22: 1716-1721.

39 van Oudheusden TR, Braam HJ, Nienhuijs SW, Wiezer MJ, van Ramshorst B, Luyer P, de Hingh IH: Poor outcome after cytoreductive surgery and HIPEC for colorectal peritoneal carcinomatosis with signet ring cell histology. J Surg Oncol 2015;111:237-242.

40 Elias D, Mariani A, Cloutier AS, Blot F, Goere D, Dumont F, Honore C, Billard V, Dartigues P, Ducreux M: Modified selection criteria for complete cytoreductive surgery plus HIPEC based on peritoneal cancer index and small bowel involvement for peritoneal carcinomatosis of colorectal origin. Eur J Surg Oncol 2014;40: 1467-1473.

41 Maggiori L, Goere D, Viana B, Tzanis D, Dumont F, Honore C, Eveno C, Elias D: Should patients with peritoneal carcinomatosis of colorectal origin with synchronous liver metastases be treated with a curative intent? A case-control study. Ann Surg 2013;258:116-121.

42 Sugarbaker PH: Intraperitoneal chemotherapy and cytoreductive surgery for the prevention and treatment of peritoneal carcinomatosis and sarcomatosis. Semin Surg Oncol 1998;14:254-261.

43 Yang XJ, Li Y, Yonemura Y: Cytoreductive surgery plus hyperthermic intraperitoneal chemotherapy to treat gastric cancer with ascites and/or peritoneal carcinomatosis: Results from a Chinese center. J Surg Oncol 2010;101:457-464.

44 Yonemura Y, Endou Y, Sasaki T, Hirano M, Mizumoto A, Matsuda T, Takao N, Ichinose M, Miura M, Li Y: Surgical treatment for peritoneal carcinomatosis from gastric cancer. Eur J Surg Oncol 2010;36:1131-1138.

45 Canbay E, Yonemura Y, Brucher B, Baik SH, Sugarbaker PH: Intraperitoneal chemotherapy and its evolving role in management of gastric cancer with peritoneal metastases. Chin J Cancer Res 2014;26:1-3.

46 Coccolini F, Catena F, Glehen O, Yonemura Y, Sugarbaker PH, Piso P, Montori G, Ansaloni L: Complete versus incomplete cytoreduction in peritoneal carcinosis from gastric cancer, with consideration to PCI cutoff. Systematic review and meta-analysis. Eur J Surg Oncol 2015;41:911-919. 